\title{
A SHORT REVIEW OF CONNECTIVE TISSUE METABOLISM
}

\author{
BY \\ H. G. B. SLACK \\ From the Rheumatism Research Centre, University of Manchester
}

(RECEIVED FOR PUBLICATION FEBRUARY 23, 1955)

Our knowledge of connective tissue metabolism is mostly very new and can at present only be gleaned from widely scattered publications. An incomplete account of collagen metabolism is included in a recent symposium edited by AsboeHansen (1954), and there are fuller reviews of mucopolysaccharide metabolism. But these accounts do not, naturally enough, consider some important and more recent information. It would, therefore, seem useful to attempt to review the present position. It has not been for want of interest that the dynamics of connective tissue should only now be receiving attention. After all, connective tissue histology is of almost venerable antiquity, and there were the earlier metabolic studies, such as that of Bywaters (1937), to show that adult connective tissue has a negligible oxygen consumption and therefore, presumably, a low metabolic activity. But two main difficulties stood in the way of biochemical progress. First, the lack of a satisfactory method of investigation, and, secondly, the difficulties inherent in separating and chemically characterizing adequate amounts of material for such studies. The first difficulty has been resolved by the more general availability of radioactive isotopes, and by rapid progress in methods of using them as tracer substances in following the progress of metabolic change. The second difficulty is still with us, and a formidable amount of work still remains to be done in devising methods of separating the connective tissue components in forms which are not grossly altered from their state in the living body, and in their chemical characterization.

\section{Metabolism of Collagen and Elastin in the Normal Animal}

(1) Collagen Fibres: "Mature" Collagen.-Rat tendon collagen metabolizes more rapidly in the young than in the old, judged by the gain and loss of isotopic glycine; its turnover is lower than that ${ }^{\circ}$ collagen from elsewhere, and that of collagen is lower than that of other tissues (Neuberger and others, $1951 ; 1953)$.

Results have also been reported indicating $\frac{\mathbb{R}}{2}$ relatively slow rate of turnover of collagen if guinea-pigs (Robertson, 1952).

(2) Soluble Collagens and Precursors of Collagen-The foregoing experiments used methods of extraction and purification of collagen which resujed in an end-product almost wholly derived from fülyo formed "mature" collagen fibres. Only in the ver young animals is the collagen likely to have include $\bar{\phi}$ some soluble or "immature" collagen, and the possible inclusion of some precursor collagen in the final extract might account for the small but definit $\vec{s}$ metabolic activity of the collagens in the young rats. The possibility that collagen changes in it metabolic behaviour with increasing age of the animal is suggested by physical differences observe in collagen obtained from young and old animals tendons (Jordan-Lloyd and Marriott, 1935; Leplat 1935). The existence of soluble, collagen-likes proteins in connective tissue has been known fo quite a long time and appears to have been first reported by Zachariadès (1900). The dissolution of collagen in very dilute acetic acid, especially thas of the tail tendon of the rat, was studied in detail by other French workers, particularly by Nageotte, ir the late 1920s and 1930s. Only a small part of the collagen goes into solution normally in dilute् acetic acid, and it is interesting to note that the proportion of collagen which so dissolves was found to decrease with age (Nageotte and Guyon, 1934) More recently, Russian workers, especiall Orekhovitch and his co-workers have studied the properties and distribution of soluble collagen in 
great variety of species and tissues. The material studied by Orekhovitch (1950) and Orekhovitch and others (1948) appears to be identical with that described by the earlier French workers. Orekhovitch called this soluble protein "procollagen", implying that it is a precursor of insoluble collagen; it occurs in relatively large amounts only in connective tissue of young animals. The presence of another type of soluble collagen was suggested by the work of Highberger, Gross, and Schmitt (1951), who found that an extract of skin made with slightly alkaline phosphate solutions contained a protein which in its appearance under the electron microscope resembled collagen. It was obviously of great importance to attempt to determine whether soluble collagens were the precursors of "mature" fully-formed collagen fibres.

An attempt to elucidate this problem was made by Harkness, Marko, Muir, and Neuberger (1954), who studied the incorporation of labelled glycine into soluble collagens extracted from the skin of very young rabbits. Several points arise from this important work. By extraction procedures three forms of collagen can be distinguished. The first, alkali-soluble collagen, is initially soluble in disodium hydrogen phosphate solutions. The second, acid-soluble collagen, is extracted by acidic buffers such as citrate $p \mathrm{H} 4$. This is identical with the "procollagen" of Orekhovitch and corresponds

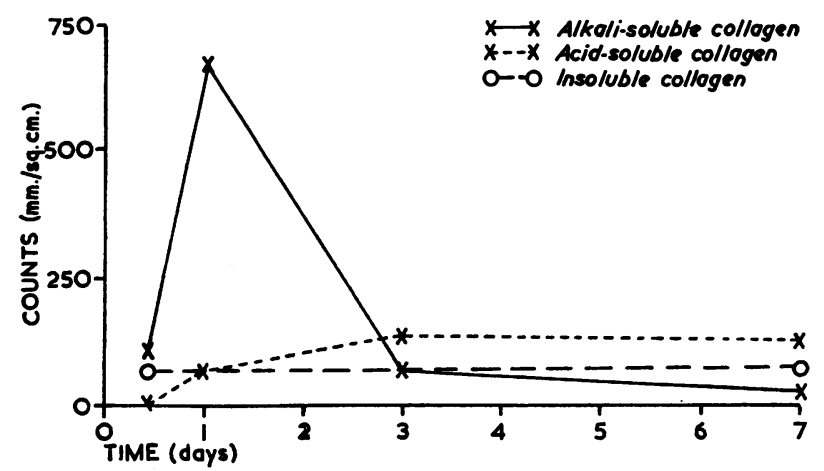

Fig. 1.-Radioactivities of glycine from skin collagens of very young rabbits fed $\left[\alpha-{ }^{14} C\right]$ glycine by mouth. (See Biochem. J., 1954, 56, 558.)

to the soluble collagen of the earlier French workers. Finally, there is the insoluble or "mature" collagen which remains after repeated phosphate and citrate extractions. Very marked differences were observed in the incorporation of labelled glycine into these three collagen fractions, and these differences are illustrated in Fig. 1. The activity of the alkalisoluble collagen rises very rapidly to a high value in the first $24 \mathrm{hrs}$ after isotope administration, and then falls sharply, so that at 3 days it is no higher than that of the insoluble collagen. In some of the experiments the activities observed in alkali-soluble collagen exceeded those found in any other protein, not excluding the plasma proteins. The rate of turnover of this collagen fraction is $\mathbf{2}$ days or less, and it seems very probable that this is the precursor of the collagen fibrils. The acid-soluble collagen, the so-called "procollagen", on the other hand shows very low activity by comparison. Also the activity of this fraction shows a slow rise in the first 3 days and at 7 days has fallen a little, so that it is about the same as the insoluble collagen. This kind of activity-time curve is not compatible with the assumption that acid-soluble collagen is a precursor of the collagen fibres. Finally, Fig. 1 shows that the activities observed in the insoluble collagen from these rabbit skins are very similar to the earlier experiments in rats, i.e. very low activities throughout with no appreciable loss of activity with time.

(3) Elastin.-This important fibrous protein is a major constituent of the larger arteries and certain spinal ligaments. Although not unlike collagen in some respects, it differs in certain staining properties, in its appearance under the electron microscope and in its amino-acid pattern. It has been shown by Bowes and Kenten (1949) to contain less arginine, lysine, hydroxyproline, and glutanic acid, rather less aspartic acid, and more valine than does either collagen or reticular tissue. There is to date only one paper on its metabolism (Slack, 1954a). In these experiments normal adult rats were injected with $[\alpha-14 \mathrm{C}]$ glycine, and killed, some 1 day, others 9 days later. Another group of rats with experimental atrophy of one hind limb were similarly treated. The aortae of the rats were dissected out, and the contained elastin was separated from other protein by first boiling under reflux for 4 days with $0.005 \mathrm{M}$ acetic acid and then trypsinizing for $24 \mathrm{hrs}$ at $37^{\circ} \mathrm{C}$. and $p \mathrm{H} 8$. The method has been shown by Tunbridge and others (1952) to free the elastin from associated collagen and give a satisfactorily homogeneous preparation for electron microscopy. The radio-activities of glycine recovered from the purified elastin were then determined. The observed radio-activities were essentially similar in both groups of rats at all time intervals and were of the same order as those found previously in bone collagen of adult rats. It therefore seems probable that in the adult rat elastin, in common with the major portion of collagen, has a very slow rate of turnover. 


\section{Changes in the Collagen Content of Tissues under Certain Physiological and Pathological Conditions}

A number of histological investigations of the changes in the supporting elements of growing tissues have been done, but very few quantitative observations are reported on the chemical constituents of these supporting elements. Observations of this kind would provide valuable indirect information on connective tissue metabolism. Abercrombie and Johnson (1946) estimated collagen chemically in degenerating and regenerating nerve, and Harkness (1952) estimated collagen in liver regenerating after partial hepatectomy. In both instances collagen formation was found to be a slow process which lagged considerably behind changes in the principal cellular elements of the tissue. Similarly in cirrhosis of the liver produced by carbon

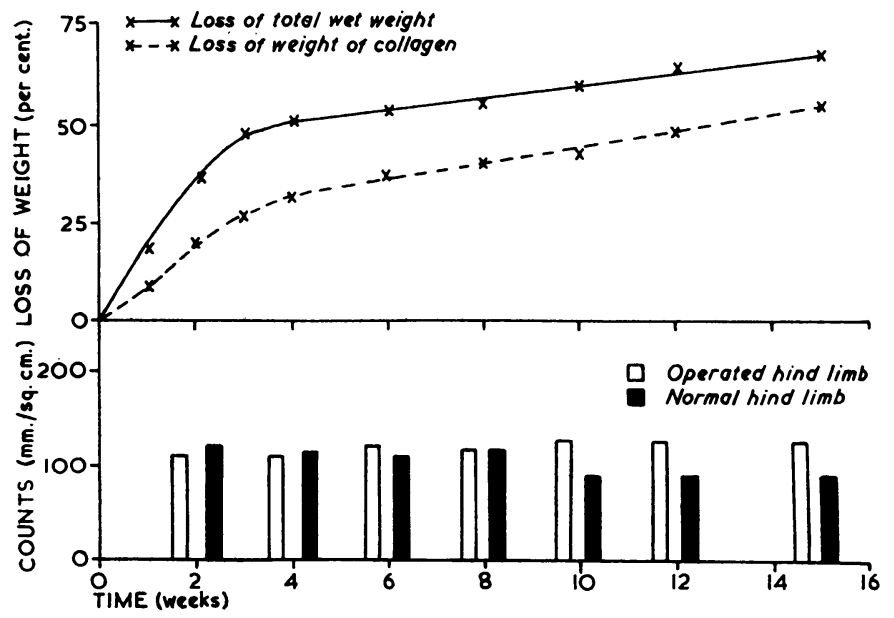

Fig. 2.-(a) Loss of total wet weight and loss of collagen (in g. per cent.) in experimental limb atrophy in adult rats.

(b) Specific activities of glycine from total collagen of operated and normal hind limbs of the same rats given $\left[\alpha_{-14} C\right]$ glycine and killed 2-15 weeks after operation. (See Clin. Sci., 1954, 13, 155.)

tetrachloride quantitative estimation of collagen showed a slow increase (Morrione, 1949). In rats treated with thiouracil there was increase in weight of the thyroid gland and of its collagen content, but again the latter increase was slower than that of the total tissue (Harkness, Harkness, and Santler, 1954). More interesting was the observation that on cessation of thiouracil treatment there was a relatively quick removal of collagen from the gland.

Much more rapid formation of collagen has been observed in the uterus of the rat during pregnancy (Harkness and Harkness, 1952). The increase in collagen content in this instance closely parallels the increase in the total wet weight, and in the puer- perium there is a very rapid fall in both total weigh of the uterus and its collagen content. Under the physiological stimulus of pregnancy there is thes great local increase in the rate of synthesis of collage $\overrightarrow{\text { F }}$ followed by an equally spectacular increase in the rate of removal or reabsorption of collagen.

Massive removal or reabsorption of collagen has also been observed in experimental limb atrophy i i the rat (Slack, 1954b). If one hind limb of the rat is immobilized by dislocation at the hip joint an avulsion of all main nerve trunks, then massive tissue wasting ensues in the limb. During the first 4 weeks after operation there is a fairly rapid loss $\$$ total wet weight followed by a long phase during which tissue wasting proceeds much more slowly. The loss of collagen from these wasting tissues of the limb follows a similar curve (Fig. 2). The rats weree injected with $\left[\alpha-{ }^{14} \mathrm{C}\right]$ glycine and killed at various time intervals up to 15 weeks after operation. Collagen activities in the tissues of the normal hind limb and wasting hind limb were determined an it was found, rather surprisingly, the the specific activities of collagen fro the two limbs were similar. Indee $\mathbb{P}$ at 10 weeks onwards from operatgr the collagen in the wasting limb sho e्f somewhat higher activity than that fể the normal control limb (Fig. 2). Fhe experimental production of atrophy a whole hind limb did not cause cessatio of collagen synthesis, and the loss collagen from the wasting tissues wour appear to be due to increased activity $\overrightarrow{\text { ff }}$ some at present unknown removâ mechanism.

To summarize, in the normal animal the greater part of collagen is metaboliz ally relatively inert. This is true at aीt ages, but it is almost certain that the proportion of total collagen which is this state of inertia, metabolically speaking, increase with increasing age. In very young actively growing animals there is a substantial amount of collagen which is in a more soluble form. Some of the forming only a small part of the total collagen everi in very young animals, is the alkali-soluble collage and this precursor is in a high state of metabolig activity. In adult tissues under normal conditions the amount of this alkali-soluble collagen must be very small indeed. But at least one important diversion from this metabolic pattern has bee recorded. This is the rapid formation and equal $\mathbb{E}$ rapid subsequent dissolution of collagen in the rat uterus in pregnancy. Information on the mets 
bolism of elastin is limited to one small series of experiments which suggest that its metabolic behaviour is similar to collagen. There is as yet no information whatever of the metabolism of the tyrosine-rich protein whose presence has been detected in bone, cartilage and skin, and which is probably present in other connective tissues.

\section{Metabolism of Mucopolysaccharides}

The substances with which we shall be concerned, here, are members of a group of high molecular weight polymers formed from glucosamine or galactosamine in combination with glucuronic acid and acetate, and which may contain ester sulphate. At present only two of these mucopolysaccharides are well characterized, hyaluronic acid and chondroitin sulphuric acid, and the greater part of metabolic studies have been concerned with these two substances. Heparin has been extensively investigated chemically, but nothing is yet known of its metabolism. There is a mounting weight of evidence indicating the presence in connective tissue of other mucopolysaccharides (e.g. Consden and Bird, 1954), but only one of these, chondroitin, has yet been adequately characterized (Davidson and Meyer, 1954). The separation and characterization of these mucopolysaccharide components of connective tissue is still at an early stage and the difficulties of the problem are increased by their close association in the tissues with protein.

That enzyme systems are involved in the sulphate exchange of cartilage chondroitin sulphuric acid has been demonstrated by Boström and Månsson (1953a). Labelled sulphate is taken up on incubating fresh costal cartilage slices in vitro at $37^{\circ} \mathrm{C}$. Previous boiling prevents this uptake of ${ }^{35} \mathrm{~S}$ and it is not shown by purified chondroitin sulphuric acid. The enzymatic exchange is inhibited by different kinds of enzyme inhibitors, especially -SH inhibitors, cortisone, and salicylic acid. A substance has been detected in liver homogenate which acts as a powerful stimulator of the sulphate exchange reaction (Boström and Månsson, 1953b). The active principle is thermo-stable and dialysable, but little else is known about it at present.

Dziewiatkowski (1949) showed that if a tracer dose of ${ }^{35} \mathrm{~S}$-labelled sulphate is given to an animal, most of it is rapidly excreted, only a small fraction being retained in the tissues. He also showed that there is a very high incorporation and relatively slow elimination of ${ }^{35} \mathrm{~S}$ sulphate in cartilage, bone and bone marrow. Since this paper there have been numerous contributions using autoradiographic techniques to localize ${ }^{35} \mathrm{~S}$ retained in the tissues.
Most of these are in vitro studies, but tissue culture technique has also been used (Layton, Frankel, and Scapa, 1950). It is clear from this work that most of the retained ${ }^{35} \mathrm{~S}$ is in the form of ester sulphate in the mucopolysaccharides of the connective tissues. Only a negligible amount occurs in other sulphurcontaining components (Boström and Åqvist, 1952). A recent contribution to this field has been the study of the distribution of ${ }^{35} \mathrm{~S}$ in fibrous tissues, cartilages and bones of the rat, after administration of ${ }^{35} \mathrm{~S}$ labelled sulphate, by Davies and Young (1954). They found the highest concentration of ${ }^{35} \mathrm{~S}$ in the cell columns of epiphyseal cartilage. The labelled sulphate had disappeared from fibrous tissues and most cartilages, except the cell column zones, by the 10th day after injection. Four hours after injection some of the sulphate was in the inorganic form, the remainder was in a form insoluble either in distilled water or in buffer solution at $p \mathrm{H} \mathrm{10.} \mathrm{This}$ fixed sulphate occurred principally in the pericellular zone and particularly in the region of the cartilage cell columns. Clearly this portion of the labelled sulphate has been incorporated into a component of the cartilaginous matrix. Furthermore, the fact that this fixed sulphate is in a form insoluble in buffer at $p \mathrm{H} 10$ suggests that it is not simple chondroitin sulphate in free form, but is probably C.S.A: bound to protein in a form not readily dissociable. This interesting observation is confirmed by Shatton and Schubert (1954), who showed that chondroitin sulphuric acid existed in cartilage largely as a mucoprotein, or two electrophoretically similar mucoproteins. They also showed that the protein component was quite certainly not collagen but is a tyrosine-rich protein.

The rate of metabolism of chondroitin sulphuric acid in rats has been directly studied using ${ }^{35} \mathrm{~S}$ labelled sulphate (Boström, 1952; Boström and Gardell, 1953). They found a rate of turnover of 16 days for the C.S.A. from costal cartilage and of 10 days for the polysaccharide from skin. They considered the latter to be chondroitin sulphuric acid, but there is accumulating evidence (Consden and Bird, 1954) that the skin mucopolysaccharide is not a single substance, and the observed turnover rates are probably the means of several mucopolysaccharides with individual metabolic rates which may differ widely.

Also using ${ }^{35}$ S-labelled sulphate, some experiments have been made to attempt to determine the turnover rates of mucopolysaccharides in normal rats and in rats with experimental limb atrophy (Slack, 1955). Very different rates of metabolism were found according to the method of extraction of the mucopolysaccharides. The rate of turnover 
of cartilage chondroitin sulphate in normal rats was in agreement with that found by Boström, namely, 16 days. This was for a cartilage fraction separated by papain digestion. Total cartilage polysaccharide, after inorganic sulphate had been removed, showed a higher activity, and there appeared to be a residual sulphated mucopolysaccharide with a relatively long rate of turnover. The mucopolysaccharides from the limb tissues also varied considerably with the extraction procedure. In the operated limbs, with massive tissue wasting, there appeared to be an overall increase in mucopolysaccharide metabolism, but the general picture is still confused. Some preliminary separation of the limb tissue mucopolysaccharides has been achieved by ionophoresis in borate buffers. Three main mucopolysaccharide components have been found and the distribution of ${ }^{35} \mathrm{~S}$ in these has been followed by scanning the electrophoretic bands after staining with Alcian blue. These quantities were then related to radioactivity by autoradiography of the bands, and also by elution and solid counting as $\mathrm{BaSO}_{4}$ after hydrolysis. The ${ }^{35} \mathrm{~S}$ appears to be distributed unevenly between these three mucopolysaccharides. Most of the activity appears to be distributed about equally between a slow moving and a fast moving component, but there is a third component of moderate speed in borate buffer $p \mathrm{H} 9.4$ which is smaller in amount but is relatively highly labelled.

Experiments using ${ }^{35} \mathrm{~S}$-labelled sulphate have provided most of the available information on mucopolysaccharide metabolism. It is relatively cheap, readily available and not too difficult to work with, but it has some disadvantages. The most important of these is that any conclusions from such experiments must be confined to changes in the ester sulphate group, since it is possible that these changes may not be correlated with changes in other parts of the molecule.

It was with this drawback in mind that Schiller, Mathews, and Dorfman (1954) have recently introduced the use of ${ }^{14} \mathrm{C}$-labelled acetate and glucose in this kind of experiment. Using starch ionophoresis they have perfected a method of isolating hyaluronic acid and a sulphated mucopolysaccharide from the skin of rabbits. The rate of incorporation of ${ }^{14} \mathrm{C}$ into the skin hyaluronic acid was found to be approximately three times as rapid as in the sulphated mucopolysaccharides, and the rate of decrease of activity was much greater in the hy luronic acid. The rate of turnover of hyaluronic acid appears, from these experiments, to be very fast indeed, about 2 days. The sulphated polysaccharide had a turnover rate of about 9 days, being of the same order of magnitude as that reported earlie by Boström and Gardell (1953) using ${ }^{35}$ S. Dorfma료 and others (1954) regarded the skin polysaccharidf as a mixture, the observed turnover rate bein probably the mean of several different rate Further developments of this kind of experiment should provide more complete information abouit the metabolism of the mucopolysaccharide molej cules.

I am indebted to Professor J. H. Kellgren for constant encouragement and many helpful suggestions and to the Nuffield Foundation for their support in studies oib connective tissue metabolism.

\section{REFERENCES}

Abercrombie, M., and Johnson, M. L. (1946). J. Neurol. Neurosum Psychiat., 9, 113.

Asboe-Hansen, G. (1954). "Connective Tissue in Health a Disease." Munksgaard, Copenhagen.

Boström, H. (1952). J. biol. Chem., 196, 477.

and Ăqvist, S. (1952). Acta chem. scand., 6, 1557.

and Gardell, S. (1953). Ibid., 7, 216.

and Månsson, B. (1953a). Ark. Kemi, 6, 23.

Bowes, J. H., and Kenten, R. H. (1949). Biochem. J., 45, 281은

Bywaters, E. G. L. (1937). J. Path. Bact., 44, 247.

Consden, R., and Bird, R. (1954). Nature (Lond.), 173, 996.

Davidson, E. A., and Meyer, K. (1954). J. biol. Chem., 211, 602.

Davies, D. V., and Young, L. (1954). J. Anat., 88, 174.

Dorfman, A. (1954). In "Connective Tissue in Health and Diseas ed. G. Asboe-Hansen, p. 81. Munksgaard, Copenhagen.

Dziewiatkowski, D. D. (1949). J. biol. Chem., 178, 197.

Harkness, M. L. R., and Harkness, R. D. (1954). J. Physiol. (Lond 123,492 .

, and Santler, J. E. (1954). Ibid., 125, 51

Harkness, R. D. (1952). Ibid., 117, 257.

Marko, A. M., Muir, H. M., and Neuberger, A. (195\&. Biochem. J., 56, 558 .

Highberger, J. H., Gross, J., and Schmitt, F. O. (1951). Proc. NA Acad. Sci., Wash., 37, 286.

Jordan-Lloyd, D., and Marriott, R. H. (1935). Proc. roy. Soc.

118, 439.

Leplat, G. (1935). Arch. Biol., Paris, 46, 339.

Morrione, T. G. (1949). Amer. J. Path., 25, 273.

Nageotte, J., and Guyon, L. (1933). C.R. Soc. Biol., Paris, 113, 1398

Neuberger, A., Perrone, J. C., and Slack, H. G. B. (1951). Biochen. J., 49, 199.

and Slack, H. G. B. (1953). Ibid., 53, 47.

Orekhovitch, K. D. (1950). C.R. Acad. Sci., U.R.S.S., 71, 521.

Orekhovitch, V. N. Tustanovski, A. A., Orekhovitch, K. D., and Plotnikova, N. Tustanovski, A. A., Orekhovitch, K. D., and

Robertson, W. van B. (1952). J. biol. Chem., 197, 495.

Schiller, S., Mathews, M. B., and Dorfman, A. (1954). Fed. Pro $\$$, 13, 290.

Shatton, J., and Schubert, M. (1954). J. biol. Chem., 211, 565. 을.

Slack, H. G. B. (1954a). Nature (Lond.), 174, 512

(1954b). Clin. Sci., 13, 155.

(1955). Biochem. J., 60, 112

Tunbridge, R. E. Tattersall, R. N., Hall, D. A., Astbury, W. T., and Reed, R. (1952). Clin. Sci., 11, 315.

Zachariadès, P. A. (1900). C.R. Soc. Biol., Paris, 52, 182. 